\title{
Differential Expression of Alternatively Spliced Neural Cell Adhesion Molecule L1 Isoforms During Oligodendrocyte Maturation
}

\author{
Kouichi Itoh, ${ }^{1 \star}$ Yoko Sakurai, ${ }^{2}$ Hiroaki Asou, ${ }^{2}$ and Masato Umeda ${ }^{1}$ \\ ${ }^{1}$ Department of Molecular Biodynamics, The Tokyo Metropolitan Institute of Medical Science, Tokyo \\ Metropolitan Organization for Medical Research, Bunkyo-ku, Tokyo, Japan \\ ${ }^{2}$ Department of Neurobiology, The Tokyo Metropolitan Institute of Gerontology, Itabashi-ku, Tokyo, Japan
}

The expression of neural cell adhesion molecules and myelin-specific molecules is precisely regulated according to cell type and developmental age. We investigated whether different isoforms of these molecules change during development of oligodendrocytes. Immature oligodendrocytes cultured from embryonic day 18 rat cerebrum were distinguished into early stage and late stage by morphological and immunocytochemical criteria. mRNA levels of the neural cell adhesion molecule L1 in late-stage immature oligodendrocytes were approximately fivefold higher than in early-stage cells, but earlystage immature oligodendrocytes predominantly expressed an L1 spliced isoform lacking two region (exon 2 and 27). Late-stage cells expressed full-length L1 identical to the neuronal form. mRNA for the neural cell adhesion molecules NCAM and MAG did not show any difference in expression pattern. These results suggest that alternatively spliced isoforms of L1 might be regulated by temporal and spatial factors during oligodendrocyte development. J. Neurosci. Res. 60:579-586, 2000. ๑) 2000 Wiley-Liss, Inc.

Key words: oligodendrocytes; neural cell adhesion molecules; L1; alternative splicing

Various intrinsic factors regulate development of oligodendrocytes, which are the myelin-forming cells in the central nervous system. Immature oligodendrocytes are identified by the expression of surface antigens recognized by the monoclonal antibodies A2B5 as oligodendrocyte progenitors (Raff et al., 1983) or anti-sulfatide (O4) and anti-galactocerebroside (O1) as immature oligodendrocytes (Sommer and Schachner, 1981). Continued maturation of oligodendrocytes results in elevated expression of the major myelin proteins, such as myelin basic protein (MBP), proteolipid protein (PLP), and myelin-associated glycoprotein (MAG; Campagnoni, 1988).

The molecular mechanisms regulating recognition between oligodendrocytes and other neural cells during the maturation of oligodendrocytes are still unclear. Pre- vious studies have reported that immunoglobulin (Ig)superfamily cell adhesion molecules are differentally expressed during differentiation and maturation of oligodendrocytes. $\mathrm{O}^{+} / \mathrm{O}^{+}$oligodendrocytes express only glycosylphosphatidylinositol (GPI)-anchored NCAM $120 \mathrm{kDa}$ (NCAM-120), but oligodendrocyte precursors express NCAM 180 kDa (NCAM-180) and NCAM 140 kDa (NCAM-140; Bhat and Silberberg, 1988). Takeda et al. (1996) have shown that alternatively spliced isoforms of the neural cell adhesion molecule L1 are expressed exclusively in nonneuronal cells, such as astrocytes and oligodendrocytes. MAG also is expressed early in the myelination process when oligodendrocytes initiate contact with axons (Trapp, 1990). Although several cell adhesion molecules have been identified at the contact zone between axons and myelinating oligodendrocytes, the molecular triggers for inducing specific adhesion molecule involved in myelin induction are still largely unknown (Colman, 1991); however, L1 has been shown to have a critical role in the peripheral nervous system (Seiheimer and Schachner, 1988; Wood et al., 1990).

To determine the expression pattern of alternatively splicied isoforms of neural cell adhesion molecule L1 during maturation of oligodendrocytes, we established a new culture system to distinguish two different stages of immature oligodendrocytes. The experiments described in this paper investigate whether expression of Ig-superfamily cell adhesion molecules, especially the alternative splicing pattern, are correlated with these two stages of immature oligodendrocytes. These studies provide the first evidence that expression of the exon 27 and exon 2 of L1 appears in late-stage immature oligodendrocytes, but both are absent

*Correspondence to: Kouichi Itoh, PhD, Department of Molecular Biodynamics, The Tokyo Metropolitan Institute of Medical Science, Tokyo Metropolitan Organization for Medical Research, Rm. 410, 3-18-22 Honkomagome, Bunkyo-ku, Tokyo 113-8613, Japan.

E-mail: itoh@rinshoken.or.jp

Received 22 November 1999; Revised 10 February 2000; Accepted 25 February 2000 
in the early stage. The results suggest that this differential expression pattern of alternatively spliced isoforms of L1 could become a useful developmental markers to distinguish these different stages of oligodendrocytes. Moreover, these changes may have functional significance in the initial mechanisms of myelination in brain.

Privious reseach has shown differential alternative splicing of exons of NCAM, L1 MAG, and MBP genes in a temporal and spatial fashion (Reyes et al., 1993; Takeda et al., 1996; Fujita et al., 1998). Each of these genes produces a family of mRNAs that encodes two or more polypeptide isoforms through alternative splicing mechanisms. The changes in expression pattern of isoforms appear to correspond to developmental changes in distinct neural cells. Exon 18 of the NCAM gene and exons 2 and 27 of the L1 gene are specifically expressed in neurons. NCAM-140 (minus exon 18) has been observed in both neuronal cells and glial cells. NCAM-120, lacking exons 14 and 16-19, and L1, lacking exons 2 and 27, have never been found in neurons, but they are present in glial cells. In addition, the VASE exon is spliced into NCAM between exon 7 and exon 8 in neural tissues. Two isoforms of MAG are the results of alternative splicing of the primary transcript in myelin (Frail and Braun, 1984). Early in the myelination, large (L)-MAG (72 kDa), devoid of exon 12 , is predominantly expressed, whereas levels of small (S)-MAG (68 kDa), containing exon 12, increase in late stages (Lai et al., 1987). MBP has multiple polypeptides varying in molecular weight from 14 to $21.5 \mathrm{kDa}$. MBP isoforms (14.0, 17.0, 18.5, and $21.5 \mathrm{kDa}$ ) have been identified whose mRNAs originate from a single gene by alternative splicing of the primary transcript (de Ferra et al., 1985; Takahashi et al., 1985; Newman et al., 1987). Our recent work indicates that different isoforms of L1 have an important role in regulating L1-dependent cell migration (Asou et al., 1999), which could have relevance for oligodendrocyte maturation and myelination.

\section{MATERIALS AND METHODS}

\section{Animals}

Pregnant rats were obtained from Japan SLC Inc. (Sizuoka, Japan). They were maintained on laboratory chow and water ad libitum. All experimental protocols were approved by the Tokyo Metropolitan Institute of Medical Science Institutional Animal Care and Use Committee according to National Institutes of Health Animal Care and Use protocol.

\section{Cell Cultures}

Immature oligodendrocyte cultures were prepared from primary mixed cell cultures of embryonic rat cerebral cortex. Briefly, the cerebral cortex from an embryonic 18-day-old rat was mechanically dissociated through $140-\mu \mathrm{m}$-pore-size stenless mesh in 10\% FCS (JRH Bioscience, Lenexa, KS) in Eagle's MEM (Nissui, Tokyo, Japan; FCS/EMEM). The dissociated cells were finally sieved through 70- $\mu \mathrm{m}$-pore-size nylon mesh (Falcon, Lincoln Park, NJ) and then were centrifuged for 10 min, $100 \mathrm{~g}$ at $4{ }^{\circ} \mathrm{C}$. Cells were resuspended in FCS/EMEM and were seeded on poly-L-lysine (PLL; $100 \mu \mathrm{g} / \mathrm{ml}$; Sigma, St.
Louis, MO)-coated 90-mm-diameter culture dishes (Griner, Germany) at a density of $1 \times 10^{7}$ cells/dish. After 7 days of culture, the cells were passaged with $0.05 \%$ trypsin in D-PBS (Nissui; first passage). Cells were resuspended in FCS/EMEM and were cultured for 7 days at a density of $8 \times 10^{6}$ cells on a noncoated culture dish. After 7 days of culture, cells were passaged with $0.05 \%$ trypsin in D-PBS (second passage), resuspended in FCS/EMEM, and cultured for 2 days at a density of $3 \times 10^{6}$ cells on a noncoated petri dish. On the second day of culture, the medium was exchanged for serum-free chemically defined medium in DMEM (Gibco BRL, Gaithersburg, MD) supplemented with $5.6 \mathrm{mg} / \mathrm{ml}$ glucose, $5 \mu \mathrm{g} / \mathrm{ml}$ insulin, 0.5 $\mu \mathrm{g} / \mathrm{ml}$ transferin, $100 \mu \mathrm{g} / \mathrm{ml}$ bovine serum albumin (BSA), 0.06 $\mathrm{ng} / \mathrm{ml}$ progesterone, $16 \mu \mathrm{g} / \mathrm{ml}$ putrescine, $40 \mathrm{ng} / \mathrm{ml}$ sodium selenite, $40 \mathrm{ng} / \mathrm{ml}$ thyroxine, $30 \mathrm{ng} / \mathrm{ml}$ triiodthyronine, with 2 $\mathrm{ng} / \mathrm{ml}$ basic fibroblast growth factor (bFGF; all ingredients from Sigma). After 5 days culture, cells were passaged with $0.05 \%$ trypsin in D-PBS (third passage) and were resuspended in serum-free chemically defined medium at a density of $2 \times 10^{6}$ cells on a noncoated petri dish in the absence of bFGF. Earlystage immature oligodendrocytes cultured for 1 or 2 day and late-stage cells cultured for 6 or 7 days in that condition were used for experiments. These procedures are necessary to eliminate neurons and astrocytes. The cells were cultured for more than 1 month for immunocytochemical and biochemical studies. Neuron and astrocyte cultures were prepared from embryonic day 17 and postnatal day 1 rat cerebral cortex, respectively. Briefly, the rat cerebral cortex was mechanically dissociated through $140-\mu \mathrm{m}$-pore-size stenless mesh in $10 \%$ FCS in highglucose DMEM (Gibco BRL; FCS/DMEM). The dissociated cells were finally sieved through $70-\mu \mathrm{m}$-pore-size nylon mesh and then were centrifuged for $10 \mathrm{~min}, 100 \mathrm{~g}$ at $4{ }^{\circ} \mathrm{C}$. Neurons were resuspended in serum-free chemically defined medium in DMEM supplemented with $25 \mu \mathrm{g} / \mathrm{ml}$ insulin, $100 \mu \mathrm{g} / \mathrm{ml}$ transferin, $100 \mu \mathrm{g} / \mathrm{ml} \mathrm{BSA}, 20 \mathrm{nM}$ progesterone, $60 \mu \mathrm{M}$ putrescine, and $30 \mathrm{ng} / \mathrm{ml}$ sodium selenite to eliminate oligodendrocytes and astrocytes and were seeded on PLL $(100 \mu \mathrm{g} / \mathrm{ml})$-coated 90$\mathrm{mm}$-diameter culture dishes at a density of $3 \times 10^{6}$. After 7 days of culture, neurons were used for experiments. Astrocytes were resuspended in 10\% FCS/DMEM and were seeded on PLL (100 $\mu \mathrm{g} / \mathrm{ml}$ )-coated $90-\mathrm{mm}$-diameter culture dishes at a density of $1 \times 10^{6}$. After 7 days of culture, cells were passaged with $0.05 \%$ trypsin in D-PBS to eliminate other cells. After resuspension in $10 \%$ FCS/DMEM, astrocytes were seeded and cultured for 7 days.

\section{Immunocytochemistry}

To determine the cellular specificity of the stagespecific early or late immature oligodendrocytes, the cells growing on a petri dish were fixed with $2 \%$ periodate-lysineparaformaldehyde solution and then processed for immunocytochemistry as previously described (Itoh et al., 1995). Antibodies used for oligodendrocyte lineage analysis were monoclonal antibodies against gangliosides (A2B5), sulfatide $(\mathrm{O} 4$,$) and galactocerebroside (O1; Sommer and Schachner,$ 1981; ATCC, Rockville, MD), polyclonal myelin basic protein (MBP; Nichirei, Tokyo, Japan), and anti-MBP monoclonal antibody (Boehringer Mannheim, Germany). 


\section{Immunoblot Analysis}

Immunoblotting was performed according to the method previously described (Itoh et al., 1995). Cultured cells were lysed with $0.5 \mathrm{ml}$ of lysate buffer: PBS containing 1.0\% NP-40, $0.5 \%$ deoxycholate, $2 \mathrm{mM}$ EDTA, $10 \mu \mathrm{g} / \mathrm{ml}$ soybean trypsin inhibitor, $10 \mu \mathrm{g} / \mathrm{ml}$ eggwhite trypsin inhibitor, $0.5 \mathrm{mM}$ AEBSF, $1.0 \mathrm{mM}$ benzamidine, $0.1 \mathrm{mM}$ leupeptin, $10 \mu \mathrm{g} / \mathrm{ml}$ pepstatin, and $1 \mu \mathrm{g} / \mathrm{ml}$ aprotinin at $\mathrm{pH} 8.0$ (Calbiochem, La Jolla, CA). The lysate was centrifuged for $20 \mathrm{~min}$ at $14,000 \mathrm{~g}$ at $4{ }^{\circ} \mathrm{C}$. The protein concentration of each lysate was measured by Micro BCA Protein Assay Reagent (Pierce, Rockford, IL). Sodium dodecyl sulfate-polyacrylamide gel electrophoresis (SDS-PAGE) was performed on 15\% polyacrylamide gels (Laemmli, 1970). To examine MBP polypeptide levels in the cells, proteins fractionated by SDS-PAGE gels were transferred to Immobilon-P (Millipore, Bedford, MA) and processed for western blot analysis with monoclonal MBP antibody and HRPconjugated anti-mouse $\mathrm{IgG}$ antibody using Ultrasuper signal reagent according to the manufacturer's instructions (Pierce). These signals were semiquantified by IPLab Gel (Scanalyitics, Inc.).

\section{Reverse Transcription-Polymerase Chain Reaction}

Total RNA was extracted from equal amounts of RNA (25 ng) and was reverse transcribed by Superscript RNaseH-reverse transcriptase II (Gibco BRL) and random primers for $60 \mathrm{~min}$ at $42{ }^{\circ} \mathrm{C}$ and heated for $10 \mathrm{~min}$ at $95^{\circ} \mathrm{C}$ to stop the reaction. The synthesized cDNA $(1 \mu \mathrm{l})$ was amplified in a total volume of $15 \mu \mathrm{l}$ with $0.5 \mathrm{U}$ AmpliTaqGold DNA polymerase (Perkin-Elmer, Norwalk, CT) in the presence of $0.25 \mathrm{mM}$ dNTP, $1 \mathrm{mM} \mathrm{MgCl}_{2}$ and 25 pmol each of two primers for exon 2 of L1 (177 bp and $192 \mathrm{bp}$ ) 5' -primer ATGGTCATGATGCTGTGGTACGT and 3' GGGTCTGCCTCTGGCTTCACA, for exon 27 of L1 (124 bp and 136 bp) 5'-primer AGGAGGACACTCAGGTAGATTCCG and $3^{\prime}$-primer GGTTTGATGTCTCCGTTGAGAGATG, for exons 4-7 (second Ig loop) of L1 (404 bp) 5' -primer GGAGTTCCGCTGGACGAAAGAT, 3'-primer AGGTAAGCACATTGGCAAAATA of the rat L1 cDNA sequences (Miura et al., 1991). Other sequences of oligonucleotides used for PCR primers as follows: NCAM-180 (272 bp): 5'-primer GGCGAGGACTTAAAAATGGACG, 3'-primer GTTTGTGTGGCATCGTTGGG; NCAM-140 (322 bp): 5'-primer TCGTCCTACTCCTGGTGGTCAT, 3'-primer GTTGGCGCTGGCTTTGCTTCTG; NCAM-120 (330 bp): 5'-primer CAGATGGGAGAGGACGGGAACT, 3'-primer CGCAGAGAAAAGCAATGAGACC; NCAM-VASE (88 bp and $118 \mathrm{bp}$ ): $5^{\prime}$-primer ACCTGCAGAACGTCCACCCGAAACATCA, 3'-primer AGGACACACGAGGCATGCCTGCGTACCAC; F3 (389 bp): 5'-primer GCTCTTGGAAACCCTGTTCCT, 3'-primer TTCTGCTATGCACTGGTACAT; MBP (170 bp): 5' -primer ACTCACACACGAGAACTACCCA and $3^{\prime}$-primer CCAGCTAAATCTGCTGAGGG; MBP exon 2 (106 bp and 184 bp): 5'-primer ACACGGGCATCCT TGGACTCCATCG, $3^{\prime}$-primer GAGCCGTAGTGGGTAGTTCTTGTG; MBP exons 5-7 (80 bp and $203 \mathrm{bp}$ ): 5'-primer CCTGTCCCTCAGCAGATTTAGC, 3'-primer AGGGAGGCTCTCAGCGTCTTGC; PLP/DM-20 (357 bp and 252 bp): 5'-primer CCAAAAACTACCAGGACTATGA, 3'- primer CAGAGCAGGCAAACACCAGGAG; and MAG (605 bp): 5'-primer GCCACGGTCATCTATGAGAGTCAGC, 3'-primer GGTGCCCAGAGATTCTGAATTCGG. The PCR products of 18S-rRNA (488 bp; Ambion, Austin, TX) and rat glyceraldehyde-3-phosphate dehydrogenase (GAPDH; 452 bp; Clontech, Palo Alto, CA) were used as an internal control. In pilot experiments, the condition was established in which the amount of PCR products increased with increasing amounts of cDNA and increasing number of cycles (approximately 35 cycles). Reaction mixtures were amplified for 28-30 cycles, each cycle consisting of $30 \mathrm{sec}$ denaturation at $95^{\circ} \mathrm{C} ; 30$ sec annealing at $56^{\circ} \mathrm{C}$ for L1, NCAM, F3, MBP, MAG, GAPDH, and $18 \mathrm{~S}-\mathrm{rRNA}$ or $65^{\circ} \mathrm{C}$ for PLP/DM20; and $60 \mathrm{sec}$ polymerization at $72{ }^{\circ} \mathrm{C}$. Ten microliters of PCR products were analyzed on 3\% NeuSieve 3:1 agarose gel (FMC) and a 4-10\% polyacrylamide gel (Tifco, Tokyo, Japan) and visualized under UV illumination after ethidium bromide staining. These signals were semiquantified by IPLab Gel.

\section{RESULTS}

\section{Immature Oligodendrocytes Can Be Distinguished Into Two Different Stages}

The A2B5-immunoreactive (IR) progenitors made up less than $20 \%$ of the cells, and $\mathrm{O}^{+} / \mathrm{O} 1^{-}-\mathrm{IR}(>80 \%) \mathrm{im}-$ mature oligodendrocytes had many processes, and the diameter of the cell body was less than $10 \mu \mathrm{m}$ at 1 or 2 days after the third passage according to the cell culture procedure described above. We therefore designated these cells as earlystage immature oligodendrocytes (Fig. 1A,D). Most of the cells cultured at 6 or 7 days after third passage were defined by $\mathrm{O}^{+} / \mathrm{O} 1^{+}$IR $(>85 \%)$ in the presence of $\mathrm{A} 2 \mathrm{~B} 5^{+}$cells $(<15 \%)$. These cells, designated late-stage, had thick processes and decreased number of processes. In addition, the cell bodies were enlarged $(>10 \mu \mathrm{m})$ in comparison to the earlystage oligodendrocytes (Fig. 1F,I).

\section{Differential Localization of MBP in Isolated Immature Oligodendrocytes}

When analyzed by indirect immunofluorescence using polyclonal MBP antibody, MBP was predominantly expressed on the cell body including nuclei in early-stage oligodendrocytes (Fig. 1B). In contrast, MBP was expressed on the tips of processes in late-stage cells (Fig. 1G). When analyzed by western blotting, early- and late-stage cultured oligodendrocytes expressed all of the molecular species of $\operatorname{MBP}(14,17$, 18.5, and $21.5 \mathrm{kDa}$ ) (Fig. 2, bottom). However, all isoforms were not expressed in the same way. The 14 and $18.5 \mathrm{kDa}$ isoforms had a plasma membrane distribution as shown in Figure 2, top. Membrane-bound $\mathrm{MBP}$, especially the $14 \mathrm{kDa}$ isoform, was highly expressed on late-stage oligodendrocytes. Therefore, two stages of immature oligodendrocytes in vitro were characterized by morphological changes and expression patterns of MBP.

To examine whether alternatively spliced isoforms of MBP genes are expressed during maturation, RT-PCR 

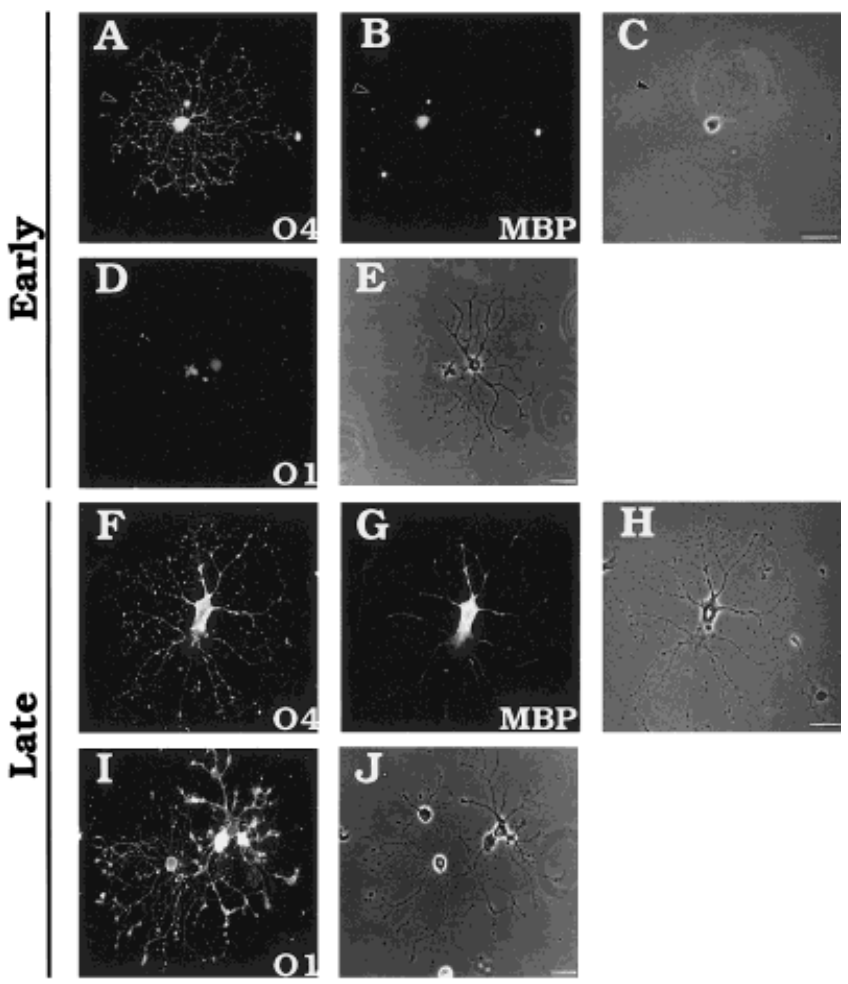

Fig. 1. Double-immunofluorescence staining of early-stage (A-E) and late-stage $(\mathbf{F}-\mathbf{J})$ immature oligodendrocyte cultures with anti$\mathrm{O} 4$, anti-O1, and anti-MBP antibodies. Note that a nuclear accumulation of MBP immunoreactivity (arrowhead in B) is faintly visible in early stage $\mathrm{O}_{4}^{+}$(A) and $\mathrm{O}^{-}{ }^{-}$(D) immature oligodendrocytes, but the expression of MBP increased, as shown in $\mathrm{G}$, in both the cell body and the cell processes of late-stage $\mathrm{O}_{4}^{+}(\mathrm{F})$ and $\mathrm{O}^{+}$ (I) immature oligodendrocytes. Corresponding phase contrast micrographs to fluoresence: C for A and B, E for D, H for F and G, and $\mathrm{J}$ for I. Scale bars $=20 \mu \mathrm{m}$.

was performed using total RNA extracted from early- or late-stage oligodendrocytes. In the analysis of MBP genes, all isoforms contained a fragment of $184 \mathrm{bp}$ or $106 \mathrm{bp}$, which was derived from exon 2 plus or minus primers, and also a fragment of $203 \mathrm{bp}$ or $80 \mathrm{bp}$, which was derived from exon 6 plus or minus primers. The results showed that the expression of MBP mRNA, including the spliced forms, was not increased in the early-stage immature oligodendrocytes (Fig. 3). These results suggested that the transcription levels of myelin genes might not be changed during development in vitro.

\section{Expression of Neural Cell Adhesion Molecule mRNA in Immature Oligodendrocytes}

To investigate mRNA levels of neural cell adhesion molecules (L1, NCAM, F3, and MAG) during developmental stages of immature oligodendrocytes, semiquantitative RT-PCR was performed and mRNA levels were analysed. The L1 gene was expressed in both stages of oligodendrocytes (Fig. 4). When PCR primers were used that amplified exons 4-7 corresponding to the second

\section{Membrane fraction A B}

kDa
14.0-

\section{Whole cell fraction}

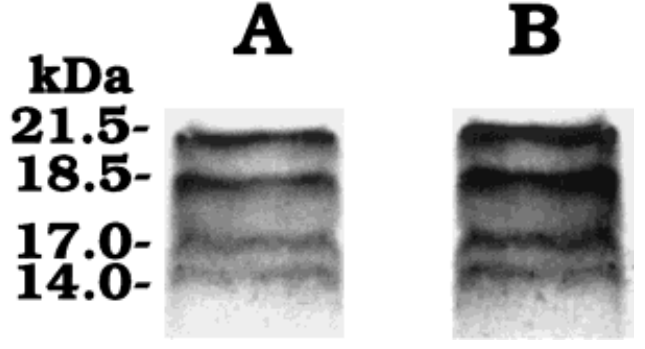

Fig. 2. Immunoblot analysis of MBP in stage-specific oligodendrocytes. Note that, in $0.5 \mathrm{ml}$ aliquots of crude plasma membrane fraction of late-stage immature oligodendrocytes (lane B) and earlystage immature oligodendrocytes (lane A; top) and sample buffersolubilized whole cell fraction of late-stage immature oligodendrocytes (lane B) and early-stage immature oligodendrocytes (lane A; bottom), samples from cultured cells have proved to be a satisfactory indicator of immunostaining by monoclonal anti-MBP antibody. The protein load on 15\% SDS-PAGE gel and in each lane was $25 \mu \mathrm{g}$.

Ig-like domain, L1 mRNA levels at late stage were approximately fivefold higher than at early stage (Table I). Three major isoforms $(180,140$, and $120 \mathrm{kDa})$ of NCAM are alternatively spliced from one NCAM gene (Cunningham and Edelman, 1990). Levels of NCAM mRNA for 120 and $140 \mathrm{kDa}$ were not dramatically different between the two stages (Fig. 4). Expression of NCAM mRNA for neuron-specific $180 \mathrm{kDa}$ with exon 18 of the NCAM gene was not observed in any of the cells. Another alternatively spliced isoform (VASE exon) at the exon 7/8 junction of the NCAM gene for the fourth Ig-like loop found by Small and Akeson (1990) was equally expressed. NCAM mRNA both with and without the VASE insert were detected in immature oligodendrocytes at each stage, though levels of NCAM with VASE were very low. Although F3 was exclusively expressed by neurons, F3 mRNA was highly expressed in late-stage oligodendrocytes, but not in early-stage cells (Fig. 4). Alternative splicing of a single gene generates two developmentally regulated MAG polypeptides $(67$ and $72 \mathrm{kDa}$; Lai et al., 1987). Difference in MAG mRNA expression for 67 and $72 \mathrm{kDa}$ was not observed in any of these cells (data not shown). 


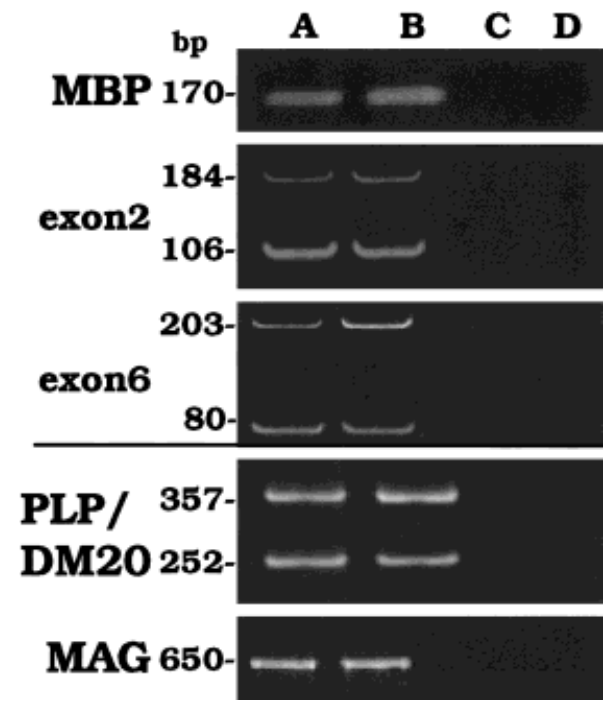

Fig. 3. RT-PCR analysis of myelin-specific genes. Numbers indicate molecular size (bp) of each band of amplified fragment for MBP, MBP with or without exon 2, MBP with or without exon 6, PLP/DM-20, and MAG. The expressions of all the spliced forms of MBP mRNA were not changed at each stage. Similarly to this, other myelin genes in PLP/DM-20 and MAG mRNA were not changed. Lane A: Earlystage immature oligodendrocytes. Lane B: Late-stage immature oligodendrocytes Lane C: Neurons. Lane D: Astrocytes.

\section{Expression of Alternatively Spliced L1 Isoforms Changed Between Early- and Late-Stage Oligodendrocytes}

An alternatively spliced variant of L1 differs by the exclusion of exon 27 in the intracellular domain (Miura et al., 1991). Another isoform of L1 lacks exon 2 in the extracellular region (Takeda et al., 1996). The exon 27 spliced region has been associated with increased cell migration but not homophilic cell adhesion (Wong et al., 1995). To determine which isoform of L1 is expressed in early- or late-stage oligodendrocytes, RT-PCR was performed using specific primers to recognize exon 27 and exon 2 of the L1 gene (Itoh et al., 1997). The two isoforms of each exon were distinguished by the different size of the PCR products (136 and $124 \mathrm{bp}$ for exon 27, 192 and 177 bp for exon 2). The full-length form with both exon 27 and exon 2 was detected only in neurons, but L1 lacking exon 27 and exon 2 was never detected in neurons. The L1 short spliced isoform is expressed in nonneuronal cells such as glial cells (Takeda et al., 1996), Schwann cells (Itoh et al., 1997), and lymphocytes (data not shown). The short isoform of L1 was predominantly detected in early-stage cells (Fig. 5A). Surprisingly, the full-length neuronal form was detected exclusively at the late stage (Fig. 5B). The full-length L1 mRNA levels in the late-stage cells were approximately eightfold higher than in early-stage cells, whereas the mRNA levels of the alternatively spliced isoform in the late-stage cells was $20 \%$ of that detected in early-stage cells (Table I). Therefore, alternatively spliced

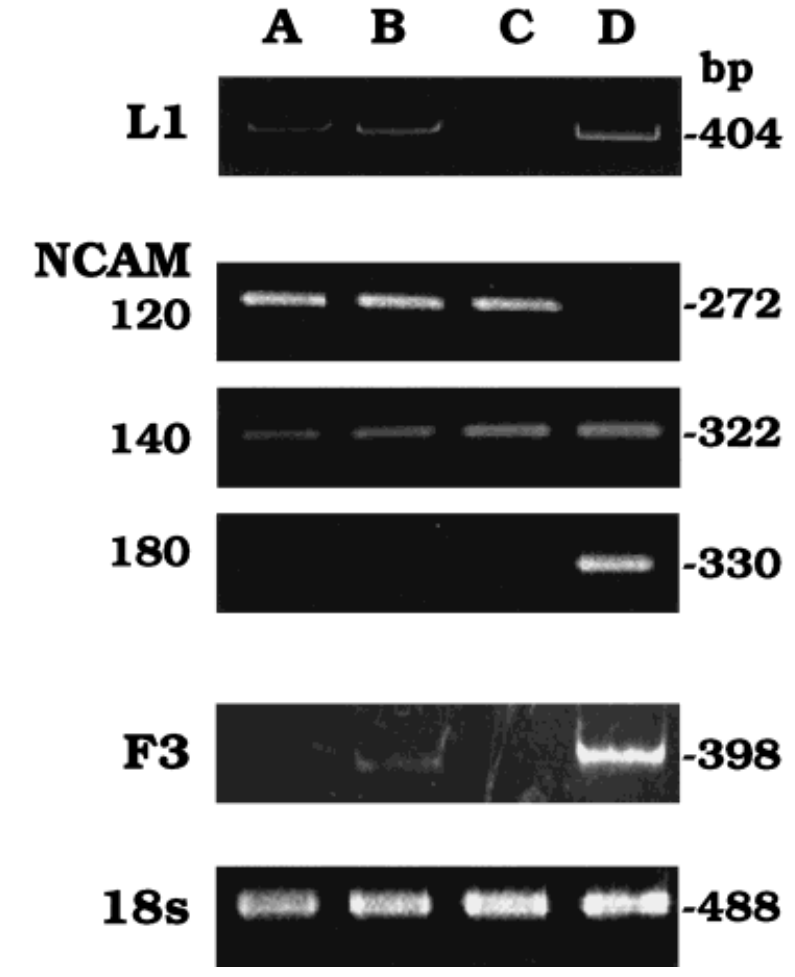

Fig. 4. L1 and F3 mRNA levels increase during maturation of immature oligodendrocytes. Lane A: Early-stage immature oligodendrocytes. Lane B: Late-stage immature oligodendrocytes. Lane C: Astrocytes. Lane D: Neurons. No significant differences in NCAM-120 and -140 expression during maturation were found by semiquantitative analysis. Neuron-specific isoform NCAM-180 was not detectable in oligodendrocytes and astrocytes. Numbers indicate molecular size (bp) of each band of amplified fragment. 18S-rRNA was used as internal standard.

isoforms of the L1 gene might be regulated by temporal factors.

\section{DISCUSSION}

In the present study, we have analyzed L1 expression during maturation of oligodendrocytes by semiquantitative RT-PCR. We first demonstrate that L1 mRNA levels in immature oligodendrocytes are increased during maturation, leading to increased expression of L1 at the cell surface, and then that expression of L1 mRNA alternatively spliced variants changes with maturation of immature oligodendorcytes.

Immature oligodendrocytes expressed all MBP alternatively spliced variants and four MBP polypeptide isoforms (Fig. 2, bottom). As is shown in Fig. 2 (top), both 14.0 and $18.5 \mathrm{kDa} \mathrm{MBP}$ appeared on the plasma membrane fraction of the oligodendrocytes. The $14.0 \mathrm{kDa}$ MBP dramatically increased with maturation relative to the $18.5 \mathrm{kDa}$ isoform. The $14.0 \mathrm{kDa}$ isoform appeared during active myelination and was the most abundant isoform throughout adulthood (Barbarese et al., 1978; Allinquant et al., 1991). Recently, Pedraza et al. (1997) 
TABLE I. Determination of Alternatively Spliced L1 Isoforms in Immature Oligodendrocytes at Early and Late Stages ${ }^{\star}$

\begin{tabular}{|c|c|c|c|c|c|c|c|}
\hline Stage & \multicolumn{2}{|c|}{ Exons 4-7 } & \multicolumn{2}{|c|}{ Exon 2} & \multicolumn{2}{|c|}{ Exon 27} & $\mathrm{n}$ \\
\hline Early & $100.0 \pm 13.1$ & NS & $100.0 \pm 21.9$ & NS & $100.0 \pm 15.0$ & NS & 4 \\
\hline
\end{tabular}

*The levels of L1 mRNA were determined by semiquantitative RT-PCR. Imaging densitometry compared the intensity of L1-specific bands. The values obtained for L1 mRNA were normalized by dividing by the values for an internal standard and the numbers (mean \pm SEM) are represented as the percentage of early stage. $P$ was assessed by Student's $t$-test; NS, not significant (vs. early stage); n, number of independent experiments. Exons $4-7$ correspond to second Ig loop. Exon 2 and 27 correspond to alternatively spliced exons, respectively.

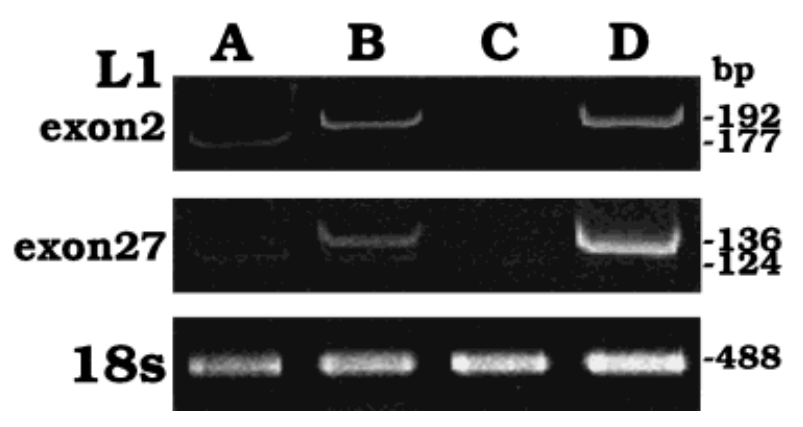

Fig. 5. Expression of L1 alternative splicing isoform is changed during maturation of immature oligodendrocytes. Exons 2 and 27 on L1 gene dominantly expressed at the early stage. Lane A: Early-stage immature oligodendrocytes. Lane B: Late-stage immature oligodendrocytes. Lane C: Astrocytes. Lane D: Neurons. Numbers indicate molecular size (bp) of each band of amplified fragment. 18S-rRNA was used as internal standard.

have reported that the 14.0 and $18.5 \mathrm{kDa}$ isoforms have a plasma membrane distribution, as expected for proteins that participate in membrane compaction, whereas the exon 2- and 5-containing 17.0 and $21.5 \mathrm{kDa}$ MBPs are distributed diffusely through the cytoplasm and are commonly observed to accumulate in the nucleus. It is generally assumed that the function of transport and localization of $\mathrm{MBP}$ is required for normal myelination in vivo. As shown by immunocytochemical studies, the distribution of MBP was clearly distinct between early- and latestage immature oligodendrocytes. Therefore, these findings suggest that MBP may play a regulatory role in oligodendrocyte maturation, in addition to myelin compaction. In addition, the expression profile of the $14.0 \mathrm{kDa}$ MBP distinguishes two stages of the immature oligodendrocytes.

L1 is expressed exclusively on postmitotic neurons in the CNS and on neurons and Schwann cells in the PNS (Schachner, 1991). Recently, several investigations indicate that L1 appeares in the B-lymphocytes (Ebeling et al., 1996) and in the distal portion of the elongating nephron (Debiec et al., 1998). In the present study, we provide the first evidence that differential expression of L1 occurs between at least two stages (early and late) of immature oligodendrocytes distinguished by our new culture techniques. We show that the L1 was expressed in a temporally dynamic and spatially different pattern during maturation. L1 mRNA levels of late-stage oligodendrocytes were approximately fivefold higher than early stage (Table I). The up-regulation and localization may make it possible to interact with an axon through L1 homophilic binding.

L1 polypeptide is encoded by a single gene $(6 \mathrm{~kb})$ composed of 29 exons, with only two spliced products as yet identified. L1 with exons 2 and 27 of the L1 gene have been specifically expressed in neurons. Recently, Takeda et al. (1996) and Jouet and Kenwrick (1995) have shown that L1 alternatively spliced mRNA isoforms are expressed exclusively in nonneuronal cells, such as glia cells and lymphocytes. The expression patterns of each isoform are restricted to the proper cell types at all times. However, it is surprising that alternative splicing of L1 changes from exon 2 and 27 minus isoform to full-length isoform during maturation of immature oligodendrocytes (Fig. 5). In our culture system, both isoforms of L1 were often detected in each stage of these cells. It is impossible to separate 100\% homogeneous populations of immature oligodendrocytes under our culture conditions. Indeed, $\mathrm{O}^{+}{ }^{+}$oligodendrocytes made up approximately $20 \%$ of the cells prepared for early stage. As a consequence, full-length L1 was detected in early-stage cell cultures.

Why is differential expression of L1 isoforms regulated during oligodendrocyte maturation by alternative splicing and translational control? The direct answer is not at all clear. However, our previous findings indicate that the RSLE (Arg-Ser-Lue-Glu) sequence corresponding to exon 27 in the L1 cytoplasmic domain plays an important role in the regulation of L1dependent cell migration (Asou et al., 1999). Splicing of the RSLE motif is conserved over several million years, the evolutionary time span between the teleost Fugu and the human L1 (Coutelle et al., 1998). Recent reports have shown that casin kinase II (CK II) immunoprecipitates with L1 and that the phosphorylation of L1 by CK II requires the presence of the RSLE insert (Wong et al., 1995). This finding suggests that phosphorylation-dependent functions of L1 in neurons might differ from those of other cells, such as Schwann cells, lacking the RSLE motif. Other investigation have reported that L1-induced neurite outgrowth depends on a cis-interaction of L1 with FGF receptors; that is, L1 and the receptors bind in the membrane and initiate a 
second messenger cascade (Williams et al., 1994). Recently, the sequence of YRSL in exons 26 and 27 conformed to a tyrosine-based sorting signal that mediated clathrin-dependent endocytosis of signal-bearing proteins. These findings suggest that cell behaviors such as migration and outgrowth are regulated by transport of L1 on the cell surface and inside cells through internalization mechanisms (Kamiguchi et al., 1998). Thus, the function of L1 is regulated by at least RSLE coded by exon 27. Therefore, we propose that the RSLE sequence might play an important role in induction of myelination by regulating intracellular signaling through L1-L1 binding between the neuronal axon and the oligodendrocyte. In contrast, the function of RSLE-deleted L1 in immature oligodendrocytes at the early stage is not completely clear. In PNS, L1 without exons 2 and 27 is involved in the initial myelination of Schwann cells (Seiheimer and Schachner, 1988; Wood et al., 1990). These findings indicate that $\mathrm{L} 1$ is involved in linear extension of Schwann cell processes along axons and engulfment of axons and segregation by Schwann cells of axons into a 1:1 relationship. This different cell behavior compared to Schwann cells and interaction with other cell surface molecules may be involved in the functional difference of L1.

By implication, L1 alternatively spliced isoforms in oligodendrocytes, which have no known physiological function, may be involved in oligodendrogliogensis and myelinogenesis. Studying this possibility may open new avenues for investigating the functions of L1 in oligodendrocyte maturation and myelination.

\section{ACKNOWLEDGMENTS}

This work was supported by Grant-in-Aid for Scientific Research of Japan Society for the Promotion of Science (K.I., M.U., and H.A.) and the Brain Science Fund, Japan (K.I.). We are grateful to Dr. R D. Fields (NIH) for critical reading of the manuscript. We thank Dr. Watanbe (The Tokyo Metropolitan Institute of Gerontology) for kindly providing PCR primers for F3.

\section{REFERENCES}

Allinquant B, Staugaitis SM, D’Urso D, Colman DR. 1991. The ectopic expression of myelin basic protein isoforms in Shiverer oligodendrocytes: implications for myelinogenesis. J Cell Biol 113:393-403.

Asou H, Takeda Y, Itoh K, Uyemura K. 1999. The RSLE sequence in the cytoplasmic domain of cell adhesion molecule L1 is involved in cell migration on L1 substrates. In: Uyemura K, Kawamura K, Yazaki T, editors. Neural development/Keio Univ. Symp for Life Sci and Med. Tokyo: Springer-Verlag. p 267-272.

Barbarese E, Carson JH, Braun PE. 1978. Accumulation of the four myelin basic proteins in mouse brain during development. J Neurochem 31:779782.

Bhat S, Silberberg DH. 1988. Developmental expression of neural cell adhesion molecules of oligodendrocytes in vivo and in culture. J Neurochem 50:1830-1838.

Campagnoni AT. 1988. Molecular biology of myelin proteins from the central nervous system. J Neurochem 51:1-14.
Colman DR. 1991. Functional properties of adhesion molecules in myelin formation. Curr Opin Neurobiol 1:377-381.

Coutelle O, Nyakatura G, Taudien S, Elgar G, Brenner S, Platzer M, Drescher B, Jouet M, Kenwrick S, Rosenthal A. 1998. The neural cell adhesion molecule L1: genomic organisation and differential splicing is conserved between man and the pufferfish Fugu. Gene 208:7-15.

Cunningham BA, Edelman GM. 1990. Structure, expression and cell surface modulation of cell adhesion molecules. New York: John Wiley \& Sons.

Debiec H, Christensen EI, Ronco PM. 1998. The cell adhesion molecule L1 is developmentally regulated in the renal epithelium and is involved in kidney branching morphogenesis. J Cell Biol 143:2067-2079.

de Ferra F, Engh H, Hudson L, Kamholz J, Puckett C, Molineaux S, Lazzarini RA. 1985. Alternative splicing accounts for the four forms of myelin basic protein. Cell 43:721-727.

Ebeling O, Duczmal A, Aigner S, Geiger C, Schollhammer S, Kemshead JT, Moller P, Schwartz AR, Altevogt P. 1996. L1 adhesion molecule on human lymphocytes and monocytes: expression and involvement in binding to alpha v beta 3 integrin. Eur J Immunol 26:2508-2516.

Frail DE, Braun PE. 1984. Two developmentally regulated messenger RNAs differing in their coding region may exist for the myelin-associated glycoprotein. J Biol Chem 259:14857-14862.

Fujita N, Kemper A, Dupree J, Nakayasu H, Bartsch U, Schachner M, Maeda N, Suzuki K, Popko B. 1998. The cytoplasmic domain of the large myelin-associated glycoprotein isoform is needed for proper CNS but not peripheral nervous system myelination. J Neurosci 18:1970-1978.

Itoh K, Stevens B, Schachner M, Fields RD. 1995. Regulated expression of the neural cell adhesion molecule L1 by specific patterns of neural impulses. Science 270:1369-1372.

Itoh K, Ozaki M, Stevens B, Fields RD. 1997. Activity-dependent regulation of $\mathrm{N}$-cadherin in DRG neurons: differential regulation of $\mathrm{N}$-cadherin, NCAM, and L1 by distinct patterns of action potentials. J Neurobiol 33:735-748.

Jouet M, Kenwrick S. 1995. Gene analysis of L1 neural cell adhesion molecule in prenatal diagnosis of hydrocephalus. Lancet 345:161-162.

Kamiguchi H, Long KE, Pendergast M, Schaefer AW, Rapoport I, Kirchhausen T, Lemmon V. 1998. The neural cell adhesion molecule L1 interacts with the AP-2 adaptor and is endocytosed via the clathrinmediated pathway. J Neurosci 18:5311-5321.

Laemmli UK. 1970. Cleavage of structural proteins during the assembly of the head of bacteriophage T4. Nature 227:680-685.

Lai C, Brow MA, Nave KA, Noronha AB, Quarles RH, Bloom, FE, Milner RJ, Sutcliffe JG. 1987. Two forms of 1B236/myelin-associated glycoprotein, a cell adhesion molecule for postnatal neural development, are produced by alternative splicing. Proc Natl Acad Sci USA 84:43374341.

Miura M, Kobayashi M, Asou H, Uyemura K. 1991. Molecular cloning of cDNA encoding the rat neural cell adhesion molecule L1. FEBS Lett 289:91-95.

Newman S, Kitamura K, Campagnoni AT. 1987. Identification of a cDNA coding for a fifth form of myelin basic protein in mouse. Proc Natl Acad Sci USA 84:886-890.

Pedraza L, Fidler L, Staugaitis SM, Colman DR. 1997. The active transport of myelin basic protein into the nucleus suggests a regulatory role in myelination. Neuron 18:579-589.

Raff MC, Miller RH, Noble M. 1983. A glial progenitor cell that develops in vitro into an astrocyte or an oligodendrocyte depending on culture medium. Nature 303:390-396.

Reyes AA, Schulte SV, Small S, Akeson R. 1993. Distinct NCAM splicing events are differentially regulated during rat brain development. Mol Brain Res 17:201-211.

Schachner M. 1991. Cell surface recognition and neuron-glia interactions. Ann NY Acad Sci 633:105-112. 
Seilheimer B, Schachner M. 1988. Studies of adhesion molecules mediating interactions between cells of peripheral nervous system indicate a major role for L1 in mediating sensory neuron growth on Schwann cells in culture. J Cell Biol 107:341-351.

Small SJ, Akeson R. 1990. Expression of the unique NCAM VASE exon is independently regulated in distinct tissues during development. J Cell Biol 111:2089-2096.

Sommer I, Schachner M. 1981. Monoclonal antibodies (O1 to O4) to oligodendrocyte cell surfaces: an immunocytological study in the central nervous system. Dev Biol 83:311-327.

Takahashi N, Roach A, Teplow DB, Prusiner SB, Hood L. 1985. Cloning and characterization of the myelin basic protein gene from mouse: one gene can encode both $14 \mathrm{kd}$ and $18.5 \mathrm{kd}$ MBPs by alternate use of exons. Cell 42:139-148.
Takeda Y, Asou H, Murakami Y, Miura M, Kobayashi M, Uyemura K. 1996. A nonneuronal isoform of cell adhesion molecule L1: tissue-specific expression and functional analysis. J Neurochem 66:2338-2349.

Trapp BD. 1990. Myelin-associated glycoprotein. Location and potential functions. Ann NY Acad Sci 605:29-43.

Williams EJ, Furness J, Walsh FS, Doherty P. 1994. Activation of the FGF receptor underlies neurite outgrowth stimulated by L1, N-CAM, and N-cadherin. Neuron 13:583-594.

Wong EV, Kenwrick S, Willems P, Lemmon V. 1995. Mutations in the cell adhesion molecule L1 cause mental retardation. Trends Neurosci 18:168172.

Wood PM, Schachner M, Bunge RP. 1990. Inhibition of Schwann cell myelination in vitro by antibody to the $\mathrm{L} 1$ adhesion molecule. J Neurosci 10:3635-3645. 